\title{
Emotionality and STEAM Integrations in Teacher Education
}

Astrid Steele

Nipissing University

Elizabeth L. Ashworth

Nipissing University

\begin{abstract}
The authors consider STEM and STEAM education initiatives as forms of integrated teaching and learning. With evidence from education research and the neurosciences, a case is made for the inherent connections between emotion and learning as essential to STEAM pedagogy. In this article, the authors' ArtScience integration project for teacher candidates (TCs) is described, and elicits the following questions: do teacher candidates (TCs) exhibit emotions directly related to the ArtScience integration project? If so, what are those emotions? How do those emotions connect with the TCs' perceptions of integration? Anecdotal evidence and collected data in the form of reflection papers are analyzed and discussed. The authors suggest that STEAM integrations take into account the importance of emotion in multidisciplinary teaching and learning.
\end{abstract}

\section{Introduction}

The art education studio is buzzing - constructions of various sizes and materials are taking shape as groups of teacher candidates (TCs) confer, then twist, glue, paint, and nudge materials into place. They have been tasked with expressing science ideas in the form of art constructions, using only found, recycled, or natural materials. This has been a very successful project in past years, and we anticipate that this class of TCs will find it a similarly intriguing learning experience. Our hope is that, by having them tackle this assignment in the role of learners, they will be inspired to offer similar integrated opportunities to their future students.

We are both professors at a faculty of education in Ontario, Canada; one of us is a visual arts instructor, the other a science education instructor. For several years, we have collaborated to bring together science and art education (with an embedded element of environmental education) 
for our TCs; we both believe that integration is foundational to successful teaching and learning. We model for our TCs our version of collegial collaboration, as well as subject integration, and the opportunity to experience our particular version of project-based learning.

While not our original intention, our ArtScience Project (see Steele \& Ashworth, 2013) aligns nicely with the STEAM initiative (science, technology, engineering, arts, and mathematics) in that it acknowledges the importance of, and provides opportunity for, crossing disciplinary borders. We would, however, add our own twist to the STEAM acronym, by suggesting that 'E for Emotion' is worthy of consideration. Emotionality as a component of the learning process has been largely ignored; Goleman (1998) points out that "our entire system of education is geared to cognitive skills . . . but when it comes to learning emotional competencies, our system is sorely lacking" (p. 244). Thus, we will make the case that emotion should be seen as situated at the very heart of learning.

In this paper, we will review literature pertinent to our discussion: the STEM and STEAM education initiatives, forms of integrated teaching and learning, and the connections between emotion and learning. We will describe our ArtScience project, which has pushed our thinking as researchers and our practice as instructors, and address the following questions: do teacher candidates (TCS) exhibit emotions directly related to the ArtScience integration project? If so, what are those emotions? How do those emotions connect with the TCs' perceptions of integration? We will provide both anecdotal evidence and collected data to address our questions, and then discuss the implications of our findings.

\section{Review of the Literature}

\section{STEM and STEAM}

The STEM (science, technology, engineering, and mathematics) initiative became popular in the U.S.A. as a response to a perceived failure of their education system to engage students in those disciplines. The result of the failure was evidenced by a lackluster science score in the 2009 international PISA study (Organisation for Economic Co-operation and Development [OECD], 2010), fewer students studying STEM topics in higher education, fewer scientists, engineers and mathematicians entering the American workforce, a decline in American technological innovation, and a steady loss of professionals to other countries offering more promising careers (see Steele, Brew, and Beatty, 2012). Machi (2009) connects the decline in STEM interest to both American industry and its military, declaring that the "education pipeline from elementary to graduate education" (p. 3) is not producing enough internationally competitive students pursuing careers in STEM. Machi's (2009) concerns are that "the leaky education pipeline impacts not only STEM industries but America's defense capabilities" (p. 3).

In response to the STEM failings, considerable corporate and federal funding has been infused into education, with specific focus on STEM topics, as a way to boost STEM-related programs and teacher professional development. Given the trajectories of other education initiatives, it is no surprise that the American STEM initiative has been taken up by other nations, including Canada. 
Science is considered a serious, sombre enterprise concerned with understanding how the world works by way of rigorous rational research and logical theorizing, and regarded as critical for the future. By contrast, the arts are believed to be concerned with beauty, not truth; the arts are subjective and personal, but not absolute necessities for the future (Eisner \& Powell, 2002). Therefore, it may seem surprising to some that educators are calling for the arts to be included in the STEM integration. In a study of scientists and artists, strong relationships were found between creativity, imagination, and the work required of scientists (van der Veen, 2012). Many scientists are extremely competent in the arts; Benjamin Franklin and Alexander Graham Bell were excellent musicians and composers (Root-Bernstein, 2003). Indeed, the separation between the arts and the sciences could be considered a contrivance perpetrated by academic elitism when one considers that life activities and choices are highly complex and integrated endeavours requiring facility in many domains. According to Venville, Sheffield, Rennie, and Wallace (2008), "knowledge in the real world is holistic, and the division of knowledge into subjects for teaching and learning in schools is an historical artifact and a pragmatic method of curriculum delivery" (p. 860).

Thus, the STEAM initiative surfaced, and is finding traction among educators, particularly those attending to the skills required to live in and contribute to 21 st-century society. Known as the four C's, these skills are: (a) creativity and innovation; (b) communication; (c) critical thinking and problem solving; and (d) collaboration (Jenson, Taylor, \& Fisher, 2010). The arts embrace the four C's, and offer many opportunities for teachers and their students to engage in complex and integrated teaching and learning, particularly when integrated with the STEM subject areas. As Eisner and Powell (2002) suggest:

Perhaps art and science are more closely related than most people believe. Perhaps many of the most important choices scientists make during the course of their work depend on the feel of the alternatives rather than on ... strict logical deductions .... Perhaps one of the primary sources of satisfaction in science is pride in craft, in the aesthetic satisfactions secured from the skillful use of tools, conceptual or otherwise. (p. 135)

In their book, From STEM to STEAM, Sousa and Pilecki (2013) suggest the public perceives STEM as having opposite characteristics from the arts. Where STEM is objective, the arts are subjective; STEM is considered logical, analytical, and useful, while the arts are seen as intuitive, sensuous, and frivolous (Sousa \& Pilecki, 2013, p. 9). Therefore, it is not surprising that arts-based classes (i.e., visual arts, music, dance, and drama) have seen a serious decline in school systems due to funding cuts. Yet the authors suggest that these are subjects that enhance creativity, problem solving, memory systems, motor coordination and analytical skills, and could provide new motivations for STEM content (Sousa \& Pilecki, 2013). The power of the arts is in their ability are to "draw on curiosity, observe accurately, construct meaning, and express one's self" (Sousa $\&$ Pilecki, 2013, p. 11). Sousa and Pilecki (2013) also draw on neuroscience research to validate further a renewed focus on the arts; for example, specific areas in the human brain are specialized to interact with the arts. After thousands of years of interactions between humans and their social and physical environments, the authors suggest that "continued existence of these [artistic] talents 
must indicate they contribute in some substantial way to our survival" (Sousa \& Pilecki, 2013, p. 13).

If the education community is moving forward with initiatives such as STEM, then the arts should be considered indispensable in that enterprise. A strong case, therefore, can be made for STEAM as a way to merge the arts with the sciences in teaching and learning contexts. The success of the STEAM initiative as enacted in real classrooms will depend largely on teachers' facility with the pedagogical processes of integration.

\section{Pedagogies of Integration}

In education, the integration of subject areas is seen as both a pedagogical asset and, particularly in the elementary panel, a practical necessity in order to meet multiple curricular expectations within a limited period. As a pedagogical strategy, integration has been around since the late nineteenth century (Cornett, 2011; Goldberg, 2012), though perhaps not so named and categorized. Regardless of labels, to integrate is to "combin[e] diverse elements into harmonious wholes with a synergistic result" (Cornett, 2011, p. 15-16).

Drake and Burns (2004) have done considerable work in the field of curricular integration, and they offer a useful categorization comprising three general approaches: multidisciplinary, interdisciplinary, and transdisciplinary. Multidisciplinary integrations focus a variety of disciplines on a specific theme but the parallel disciplines themselves retain their integrity; for example, the theme of environmental sustainability might be addressed separately in a variety of disciplines in a school year. Interdisciplinary learning occurs when common knowledge, big ideas, and common skills are embedded in a variety of subject areas, and the specific disciplines themselves begin to blur. For example, groups of students who are designing and building a passive solar water heater make use of science and technology knowledge and skills, as well as communication skills - these learnings are found across the disciplines. Transdisciplinary integrations are arguably the most difficult for teachers to facilitate (given the requirement to attend to prescribed curricula); however, they are likely the most intriguing and engaging for students. They focus on student interests and questions in real life contexts and are most often enacted through project-based inquiries. The boundaries of disciplines become porous, with knowledge and skills required to complete the project coming from many sources; for example, a class might work to design, build, and place duck nesting boxes in a local wetland. Drake and Burns (2004, p. 14) suggest that when working within the transdisciplinary approach, students go beyond the minimum required effort, realize connections between disciplines, and are able to apply their learning to authentic problems. They also exhibit improved retention, fewer behavior problems, and lower absenteeism.

Some concerns have been expressed over the integrity of the disciplines within integrations. Venville, Wallace, Rennie, and Malone (2002) ask: if students do not attend to specific disciplines, but rather work within a range of disciplines, does this lead to a softer or watered down version of any given discipline? Do integrations lower the status of specific disciplines? Does science become less rigorous when combined with visual arts? To answer these specific questions, Edwards (2008) coined the term artscience, which he defines as "the fused 
method ... at once aesthetic and scientific - intuitive and deductive, sensual and analytical, comfortable with uncertainty and able to frame a problem, embracing nature in its complexity and able to simplify nature in its essence" (p. 7). Certainly, integrations have a great deal to offer in terms of content and skill acquisition within the cognitive domain; however, as Edwards (2008) suggests, integrations also connect learning with the affective domain.

\section{Emotions and Learning}

The traditional Cartesian perspective that pitted emotion against reason such that "emotions disrupt logical processes" (Scheindlin, 2008, p. 348) seemed to maintain its hold over education for a long time. As many educators would agree, it is far easier to teach and assess content knowledge than to address and assess students' feelings about learning. Our first foray into thinking about emotion as an element of the learning process came from reading McGeehan (2001) wherein she referred to findings of how the neurosciences addressed learning, particularly the claim that "emotion is the gatekeeper to learning" (p. 8). This opened our gateway to an evolving understanding of the importance of emotion in the teaching and learning process.

The term emotion has a variety of definitions; however, we take Mega, Ronconi, and De Beni's (2014) suggestion that emotions are a process comprised of affective, cognitive, psychological, and behavioural elements. The connection between emotional involvement and learning was identified by Bloom, Engelhart, Furst, Hill, and Krathwohl (1956) in which Bloom's Taxonomy of the cognitive domain was first presented. The affective domain was then further explored and categorized by Krathwohl, Bloom, and Masia (1973). Even though Bloom et al. (1956) insisted that there was no fundamental distinction between the cognitive domain and the affective one, the importance of the affective domain in teaching and learning remained unrecognized. Goleman (1997), in his work on emotional intelligence, similarly claims that the emotional and the rational minds work together:

The emotions . . matter for rationality. In the dance of feeling and thought the emotional faculty guides our moment-to-moment decisions, working hand-in-hand with the rational mind, enabling . . . thought itself. Likewise, the thinking brain plays an executive role in our emotions . . . In a sense ... we have two brains, two minds - and two different kinds of intelligence: rational and emotional . . . intellect cannot work at its best without emotional intelligence. (p. 28)

Traditionally, research into the relationship between emotion and learning has focused on reducing negative emotions such as text anxiety (White, 2013). More recently, the relationships between emotions, motivation, cognition, and academic endeavours have garnered considerable interest. Researchers have considered, with increasing complexity, the significance of a spectrum of emotions in the education arena. Emotions affect long-term memory (Cahill \& McGaugh, 1995); positive emotions seem to support broader attention, focus, and cognition (Pekrun, Elliot, \& Maier, 2009), whereas negative emotions decrease cognition (Fredrickson \& Branigan, 2005). Talmi, Anderson, Riggs, Caplan, and Moscovitch (2008) confirmed that emotion focuses attention and enhances memory, and emotion and attention seem to work together to establish memory - 
hence the capacity to learn. Shen, Wang, and Shen (2009) proposed "[the] Human brain [functions] not just as a purely cognitive information processing system, but as a system in which both affective functions and cognitive functions are inextricably integrated ... learning almost always occurs during an emotional episode" (p. 176-177).

Based on their findings, Shen et al. (2009) posited a theoretical framework for how specific emotions might control or shape learning. They suggest four quadrants based on two perpendicular axes that act as continua. The horizontal valence axis moves from displeasure to pleasure; the vertical arousal axis moves from sleepy to high arousal. Specific emotions can then be oriented in one of the four quadrants; for example, interest lies in the pleasure/high arousal quadrant, while boredom lies in the displeasure/sleepy quadrant. The researchers found that engagement and confusion were the most important and frequently occurring emotions in learning (Shen et al., 2009). This finding might resonate with educators since engagement is a desirable emotion in learning, and confusion is a likely emotional prerequisite for engagement as the learner seeks to understand an idea or solve a problem.

How do these findings and subsequent discussions inform educators working with STEAM curricula? Scheindlin (2008) suggests that educators must attend to the importance of both knowing and feeling:

The type of learning that influences life choices, moral activity, and spiritual sensitivity is both affective and cognitive, and a teacher seeking such influence on a student's life must therefore give attention to the ways in which the student's affective and cognitive experience are coupled. (p. 344)

Scheindlin (2008) goes on to suggest what that coupling might look like in a classroom, in such a way that emotion, creativity, and content knowledge are merged in a lesson:

When students probe the innards of an insect in science class . . they should also be probing their surprise, confusion, disgust, compassion, or intrigue, and they need to be encouraged to give nuanced expression to those emotions . . . students can explore their own reactions of surprise, amazement, wonder, and awe through discussion and writing. (p. 358)

Scheindlin (2008) urges a non-traditional direction in teaching science. Along with content knowledge and skills, students are encouraged to view and reflect on their learning through the lenses of emotion and ethics. In essence, Scheindlin (2008) is suggesting a STEAM learning model that merges subject integration and emotionality. We believe that our ArtScience project provides such a learning opportunity for our TCs. In the spirit of exploration into the connections between teaching, learning, and emotion, we offer a detailed description of the project in the following sections. 


\section{The ArtScience Integration Assignment}

Our ArtScience project came about as an applied integration opportunity when we as instructors realized that one of the assignments in our two separate courses (art education and science education) had a great deal of overlap. In our praxis, we both recognize the importance of combining sciences with arts; for example, Fowler (1996) points out:

One of the arts' most important contributions to the development of young people is the cultivation of their emotional and spiritual well-being .... the arts introduce us to human perceptions and understanding we could not acquire any other way .... we are creatures of feeling as well as thought, and schools that recognize this fact, and address it, are better schools. Science and technology do not [always] tend to our spirit, but the arts do. That is their role, and it is why and how they complement and counterbalance the rest of the curriculum. (p. 53-54)

With an integration of science and art in mind, we asked the Dean of our faculty to schedule our classes such that the same TCs would be taking both their art and science education classes concurrently, thus affording the opportunity to explore integration and collaboration through this project.

\section{Description of the Teacher Candidates (TCs)}

Because the project spans five years and numerous semesters, and data was not collected formally in all of the semesters, we offer an informal description of the TCs in the project. The TCs in our classes are in a two-year Bachelor of Education program. They are studying to teach at the Junior/Intermediate level (Grades 4 through 10), and anticipate teaching in contexts where they will likely be responsible for multiple subject areas. The TCs are generally in their mid-twenties, though a handful are older, having decided to embark on a second career, and are in the consecutive education program (they have completed an undergraduate degree as prerequisite to entering the Faculty of Education). Generally, at the Junior/Intermediate level in our program, there is a preponderance of women preparing for teaching careers. Classes tend to consist of 30 to 40 TCs.

\section{The Assignment}

The ArtScience assignment requires self-selected groups of three to four TCs to first consider the relationship between science and technology, and how this relationship impacts societies and environments (STSE). They must choose specific topics from the Ontario science curriculum documents for Grades 4 through 10 (Ontario Ministry of Education, 2007, 2008). For example, using the Grade 6 unit on Flight to explore Bernoulli's Principle and the technologies of flight, the TCs examine the costs and benefits of flight to society and on the environment. Flight allows fast and efficient medical evacuations, and airplanes are critical in fighting forest fires; however, many people are financially unable to fly anywhere, leading to a further widening of the 
gap between rich and poor. Further, airplane exhaust leaves an enormous $\mathrm{CO}^{2}$ footprint in the atmosphere, contributing to climate change.

Working with ideas such as these, the TCs are then tasked in their art class to create a construction that illustrates and clearly displays their STSE ideas. They must show their process work (i.e., sketches, lists, inspirations, progress photos), and as a way to model anti-consumerist thinking and strategies the TCs are further directed to use only natural and/or recycled materials for their constructions. The constructions must also attend to elements and principles of design outlined in the Ontario curriculum documents for visual arts (Ontario Ministry of Education, 2009, 2010). Interactive components within the constructions are encouraged. For example, a clothesline that actually moves on a pulley system or flaps might reveal STSE information.

Along with their process work, the TCs must submit a two to three page reflection paper in which they discuss questions related to the assignment. What did they like or dislike about the assignment? What did they learn about integration? What design considerations were made in the planning and creation of the construction? What challenges and opportunities arose through the use of natural and/or recycled materials? How might they create such a learning opportunity for their own students? The TCs were not specifically asked to speak to their range of emotions during the completion of the assignment, an item that is discussed later in the paper.

The STSE information, process work, construction, and reflection paper were assessed using a rubric where separate sections were made for science and art foci. Although the instructors marked these sections separately, the group discussions about integration, along with teaching and learning considerations, were marked collaboratively. Analysis of the reflection papers did not commence until after the final course marks were submitted at the end of the semester.

In the analyses that follow, we are guided by our original questions: Do TCs exhibit emotions directly related to the integration project? If so, what are those emotions? How do those emotions connect with the TCs' perceptions of integration? As well, we remained open to ideas that emerged from the data that we did not anticipate. For this paper, we analyze and present data from sixteen reflection papers from the most recent iteration of the ArtScience Project.

\section{Data and Analysis}

\section{The Resulting Constructions and Reflections as Data}

Over the years, we have received a wide range of creative, original, and thoughtful art constructions tackling STSE topics as diverse as ocean pollution, mining, and microscopy. The accompanying planning notes, process work, and reflection papers have offered insight into the evolving thinking of the TCs as they make the transition from students to teachers.

The constructions and the reflection papers are considered formal data in our project; they have been thoughtfully designed and modified over the years as part of the ArtScience assignment with a view to eliciting specific information, and they have been carefully collected and analyzed. We consider our (the Instructors') anecdotal observations to be informal data; these are personal observations and intuitions based on our experience with the project over the course of several years. 


\section{The TCs' Understanding of Integration}

We begin our analysis by exploring the TCs' emerging understanding of integration as a pedagogy. While we did not present this project as a STEAM initiative to the TCs, we recognize that the ArtScience project could be considered a typical STEAM assignment.

We found many comments advocating that subject integration is beneficial to both students and teachers. We expected to find this in the data, partly because the utility of integration and its impact on learning become evident to the TCs during their project work, and partly because this is what they have been taught in theory at the faculty. The TCs addressed those issues on which their training has taught them to concentrate and for which they have been given vocabulary and permission - such as curriculum expectations, student engagement, and assessment. Words and phrases as descriptors of integration were found throughout the reflection papers, including creative, hands-on, authentic, rich tasks, improve learning and understanding, and multiple intelligences. A number of full responses are provided below which are representative of numerous similar comments from all 16 reflection papers (quotes are followed by the group number in brackets).

Our understanding of integration prior to this experience was that integrating lessons with multiple subjects would save us time in the classroom, especially as J/I candidates expected to teach a wide range of subjects. Through this task, we could see that integration is also a powerful tool to create an enriching experience for students, which is ultimately what we strive for as educators. (1)

By connecting different curricula and unifying concepts, students are able to make meaningful connections and engage in their own learning. Furthermore . . . teachers have the opportunity to design rich tasks that further help to internalize concepts. (4)

Collaborative group work as well as time to analyze, explore, create, problem solve. (3)

The TCs recognized that integration opened many doors to other subject areas; however, they addressed the ArtScience integration very specifically in the reflection papers. The comments below provide insight into their understanding of the strengths of merging visual arts with science and technology in particular:

Many would be quick to assume that the two (art and science) cannot coincide since science is often tagged as facts and logic, while art is for the creative right-brained thinkers. While there is some truth to these assumptions, this project is great evidence that these two subjects do in fact complement each other extremely well. (1)

We had to think critically, not only about the science content (in regards to STSE) but also about what object we would create to symbolize this unit and how we would integrate the science information onto the art piece. (7) 
We were curious to know where the ArtScience project might be positioned within the categories outlined by Drake and Burns (2004). Is it a multidisciplinary project, interdisciplinary, or trans-disciplinary project? We believe that it falls somewhere between inter- and transdisciplinary integration: it is project-based, as are many trans-disciplinary integrations, but the two subject areas remain distinct in the assessment as would be expected in an interdisciplinary integration. In structuring and assessing our ArtScience integration, we merged the project work, but kept the assessments separate, as this seemed the most appropriate way of addressing our two very separate course requirements at the faculty.

It is not surprising that the TCs' view of integration reflects their particular experience; however, we hope that they come to realize that integrations can take many forms.

When assessing our students, as demonstrated in this assignment, it is important to provide students with expectations from both the science and art expectations. Whether you provide a checklist, rubric or another form of assessment, the task should have an equal balance of science and art. (13)

The specific expectations from the science unit are much more specific, detailed, and rigid compared to the visual arts specific expectations - which allow for more creative freedoms.

Our experience as educators in public education, prior to our work at the faculty of education, was that the arts held a secondary position to subjects seen as leading to better employment or careers, such as the sciences and maths. We certainly hope that, despite funding cuts and heightened attention to literacy and numeracy test scores, the arts will come to be equally valued in education. The STEAM integration initiative holds considerable promise in this regard.

\section{The TCs' Emotional Responses to their ArtScience Integration Experience}

While eliciting the TCs' perspectives on integration has always been important to our research, it is more recently that we have been attending to the emotionality inherent in projectbased learning in general, and the ArtScience project in particular. In their reflection papers, the TCs addressed those elements to which they have been introduced as fundamental to teaching and learning. Emotion is clearly not among them, as evidenced by a lack of description about how they 'felt' during the project. Phrases that indicate that they themselves were excited, or enjoyed the project appeared in less than half of the data; however, some groups did provide evidence of emotionality:

None of us has a creative bone so it was great to see this come to fruition. (8)

Fun and enriching experience. (3)

We had a great time creating our art/science project. (10) 
Wonderful learning process. (11)

Two groups realized the potential of emotion for their future students:

Integration is most successful when students are excited and interested in the work they are completing, and will generally result in a higher quality product. (9)

By integrating art and science, you are making science appealing to artistic students and getting students who love science engaged in art. (5)

There was some evidence in the reflection papers of initial confusion and difficulty at the outset of the project work:

A bit of a rough start. (3)

Started out a little difficult. (10)

We went into science thinking that it would be impossible to integrate arts into it. (2)

These comments seem to align with Shen et al.'s (2009) findings that confusion is a frequent emotion in the learning process.

We have noticed this confusion over the years as it is seems to be a requisite step in the project: thinking past uncertainty towards an understanding of the project and a plan for its implementation. We suspect that the initial confusion surfaces as the TCs realize the project is not just a 'make-work' assignment providing little in the way of intellectual and creative challenge. Instead, they are faced with challenges on several fronts: thoughtful consideration of a topic through the STSE lens, merging thinking between science and art, constructing with natural and/or recycled materials, and working collaboratively. We have learned not to see this as a failing of the assignment, but a necessary step in the overall process, leading to engagement in the work and considerable pride of accomplishment in the final product.

Since the TCs' reflection papers did not provide significant evidence of their understanding of emotion as an important ingredient in the teaching and learning process, it is at this point that our own anecdotal evidence becomes useful. When the project is first assigned, most TCs react with various degrees of scepticism and uncertainty: merging the disparate subjects of art and science? Designing and creating an interactive construction that portrays STSE ideas? These hurdles elicit confusion and require suggestions and encouragement from the instructors. However, once the groups have begun the process of thinking in terms of STSE, and the design of the construction is underway, their emotions become positive. The TCs display engagement, humour, and even joy, as they describe plans for their constructions. There are also moments of frustration and annoyance during the construction process; for example, when a glued wing breaks off an airplane, or the papier-mâché does not dry quickly enough. The strongest emotions are often evoked when the groups bring their art final products into the classroom to be displayed and 
presented. This is when pride of accomplishment and enjoyment in the project are most evident, as TCs point out the intricate and creative details of their constructions: the ore cars that move along the track in the mine or the hidden dens of mice and foxes. The construction presentations to their classmates are met with clapping, happiness, and humour.

Given that research tells us that emotions are gateways to learning (McGeehan, 2001), that they enhance long-term memory (Cahill \& McGaugh, 1995), and they focus attention and cognition (Pekrun, Elliot, \& Maier, 2009), our initial exploration of emotionality indicates that the ArtScience integration assignment has a tremendous impact on the TCs' understanding of subject integration and on their future practice. Recalling Scheindlin's (2008) urging that educators attend to the importance of both knowing and feeling, the evolving emotions connected to a STEAM integration make for memorable learning.

\section{Shortcomings of the ArtScience Data}

We recognize that the ArtScience project data, both formal and informal, has shortcomings, such that our analysis might be questioned on several points. For this paper we are using only data from one semester-two classes - within a much larger project. With only sixteen groups constructing and reporting, our data pool was quite small, and may not be representative of other subject integration projects. In addition, we need to become rigorous in recording our anecdotal observations. Currently these seem to be the best source of evidence for emotionality in teaching and learning, and they should carry more qualitative legitimacy. That said, if we want to collect descriptive data of emotionality, we need to provide the TCs with encouragement, permission, and reason to address their emotions as they work through the assignment. Up to this point, we have been largely interested in integration pedagogies; however, we see emotionality as it connects to teaching and learning in general, and integrations specifically, as a new direction for our research. We should address this aspect of the project outright with the TCs. We do not have evidence that this assignment has been pivotal in TCs' future work (e.g. integration of subject areas) because we have not followed them into their careers; we can only maintain the assumption of the project's importance to the TCs.

\section{Conclusion}

Our experience and our research exploration of the ArtScience integration assignment tell us that authentic learning is an integrated endeavour requiring knowledge and skills in multiple disciplines, as well as an emotional investment in that learning. As teachers, we have long sensed that the sciences and maths have important connections to each other and to the arts. Hence, the STEM and STEAM initiatives resonate with many educators who recognize the educational enrichment inherent in crossing disciplinary borders by way of various forms of integration. Discipline separations may serve the infrastructures of schooling, and enable disciplinary elitism, but they do not reflect authentic living and learning. Indeed, authentic living and learning are entangled with emotions, and we recognize that in our education enterprises this should be 
acknowledged and addressed. Emotions are more than an adjunct to the learning process; they should be addressed by educators as essential and central in education.

The STEAM initiative brings with it added possibilities for emotionality. Merging the arts with the sciences, particularly in project-based pedagogies that require a broad range of knowledge and skills, affords increased opportunities to challenge both cognitive and affective processes. The result is an effective strengthening of the teaching and learning process for teachers and students alike.

Negative emotions (e.g., confusion, scepticism, and uncertainty) and positive emotions (e.g., enjoyment, excitement, and engagement) are necessary to the learning process. This is borne out not only by experience but also by the neurosciences. Researchers such as Shen et al. (2009) are providing detailed frameworks for nuanced understanding of the emotions that accompany and drive learning. It becomes important that educators realize the power of a wide range of emotions necessary for learning; emotionality should become part of the pedagogical discussion at faculties of education and in teacher professional development.

At the outset, we asked if the TCs exhibited emotions directly related to the integration project, and the answer was in the affirmative. Most certainly, as described in detail in the analysis, the TCs display a variety of strong emotions, and overwhelmingly their positive emotional experience with the ArtScience project leave them with a positive perception of the science and art integration assignment. In essence, they enact the real connections between the STEAM initiative and the importance of emotions to teaching and learning.

Thus, we wonder if the 'E' in STEAM (which stands for engineering in the acronym) might not also be considered to represent the emotionality that an art integration brings to the mix. Without compromising the importance of engineering, but as a reminder of the importance of emotions, we suggest $\mathrm{E}^{2}-\mathrm{STE}^{2} \mathrm{AM}$. Merging STEM with the arts, and validating emotion as a requisite component of the learning process in both its cognitive and affective aspects, becomes a way forward to provide meaningful and authentic learning opportunities for our TCs and for their future students.

\section{References}

Bloom, B. S., Engelhart, M. D., Furst, E. J., Hill, W. H., \& Krathwohl, D. R. (1956). Taxonomy of educational objectives. Handbook I: The cognitive domain. New York, NY: Longman.

Cahill, L., \& McGaugh, J. L. (1995). A novel demonstration of enhanced memory associated with emotional arousal. Consciousness and Cognition, 4(4), 410-421.

Cornett, C. (2011). Creating meaning through literature and the arts: Arts integration for classroom teachers (4th ed.). Boston, MA: Pearson.

Drake, S. M., \& Burns, R. C. (2004). Meeting standards through integrated curriculum. Alexandria, VA: ASCD.

Edwards, D. (2008). Artscience: Creativity in the post-Google generation. Cambridge, MA: Harvard University Press.

Eisner, E., \& Powell, K. (2002). Art in science? Curriculum Inquiry 32(2), 131-159. 
Fredrickson, B. L., \& Branigan, C. (2005). Positive emotions broaden the scope of attention and thoughtaction repertoires. Cognition \& Emotion, 19(3), 313-332.

Fowler, C. (1996). Strong arts, strong schools: The promising potential and shortsighted disregard of the arts in American schools. New York, NY: Oxford University Press.

Goldberg, M. (2012). Arts integration: Teaching subject matter through the arts in multicultural settings (4th ed.). Boston, MA: Pearson.

Goleman, D. (1997). Emotional intelligence: Why it can matter more than IQ. New York, NY: Bantam Books.

Goleman, D. (1998). Working with emotional intelligence. New York, NY: Bantam Books.

Jenson, J., Taylor, N., \& Fisher, S. (2010). Critical review and analysis of the issue of "Skills, Technology and Learning": Final report. Toronto, ON: Ministry of Education of Ontario.

Krathwohl, D. R., Bloom, B. S., \& Masia, B. B. (1973). Taxonomy of educational objectives, the classification of educational goals. Handbook II: Affective domain. New York, NY: David McKay.

Machi, E. (2009). Improving U.S. competitiveness: With K-12 STEM education and training. Washington, DC: The Heritage Foundation.

McGeehan, J. (2001). Brain compatible learning. Green Teacher, 64, 7-12.

Mega, C., Ronconi, L., \& De Beni, R. (2014). What makes a good student? How emotions, self-regulated learning, and motivation contribute to academic achievement. Journal of Educational Psychology, 106(1), 121-131.

Organisation for Economic Co-operation and Development. (2010). PISA 2009 results: Executive summary. Retrieved from http://www.oecd.org/edu/pisa/2009

Ontario Ministry of Education. (2007). Science and technology: Grades 1-8, revised. Toronto, ON: Queen's Printer for Ontario.

Ontario Ministry of Education. (2008). Science: Grades 9 and 10, revised. Toronto, ON: Queen's Printer for Ontario.

Ontario Ministry of Education. (2009). The arts: Grades 1-8, revised. Toronto, ON: Queen's Printer for Ontario.

Ontario Ministry of Education. (2010). The arts: Grades 9 and 10, revised. Toronto, ON: Queen's Printer for Ontario.

Pekrun, R., Elliot, A. J., \& Maier, M. A. (2009). Achievement goals and achievement emotions: Testing a model of their joint relations with academic performance. Journal of Educational Psychology, 101, $115-135$.

Root-Bernstein, R. (2003). The art of innovation: Polymaths and universality of the creative process. In L. V. Shavinia (Ed.), The International Handbook of Innovation (pp. 267-278). Oxford, UK: Elsevier Science.

Scheindlin, L. (2008). Integrating cognition and emotion: Yirat Shamayim and the taxonomies. Journal of Jewish Education, 74, 343-363.

Shen, L., Wang, M., \& Shen, R. (2009). Affective e-learning: Using "emotional" data to improve learning in pervasive learning environment. Educational Technology \& Society, 12(2), 176-189. Retrieved from http://www.jstor.org/stable/jeductechsoci.12.2.176

Sousa, D. A., \& Pilecki, T. (2013). From STEM to STEAM: Using brain-compatible strategies to integrate the arts. Thousand Oaks, CA: Sage.

Steele, A. \& Ashworth, E. L. (2013). Walking the integration talk: An ArtSci project. The Canadian Journal for the Scholarship of Teaching and Learning, 4(2), 1-15.

Steele, A., Brew, C. R., \& Beatty, B. R. (2012). The tower builders: A consideration of STEM, STSE, and ethics in science education. Australian Journal of Teacher Education, 37(10), 118-133.

Talmi, D., Anderson, A. K., Riggs, L., Caplan, J. B., \& Moscovitch, M. (2008). Immediate memory consequences of the effect of emotion on attention to pictures. Learning \& Memory, 15(3), 172-182.

van der Veen, J. (2012). Draw your physics homework? Art as a path to understanding teaching in physics. American Educational Research Journal, 49(2), 356-407. 
Venville, G. J., Sheffield, R., Rennie, L. J., \& Wallace, J. (2008). The writing on the wall: Classroom context, curriculum implementation, and student learning integrated, community-based science projects. Journal of Research in Science Teaching, 45(8), 857-880.

Venville, G. J., Wallace, J., Rennie, L. J., \& Malone, J. A. (2002). Curriculum integration: Eroding the high ground of science as a school subject? Studies in Science Education, 37, 43-84.

White, C. J. (2013). Higher education emotions: A scale development exercise. Higher Education Research \& Development, 32(2), 287-299. 